\title{
Prospecting responsible technology paths: management options for an appropriate societal embedding of medical neuroimaging
}

\section{Authors:}

Marlous E. Arentshorst. Athena Institute for Research on Innovation and Communication in Health and Life Sciences. VU University Amsterdam. De Boelelaan 1085, 1081 HV Amsterdam, the Netherlands.

Tjard de Cock Buning. Athena Institute for Research on Innovation and Communication in Health and Life Sciences. VU University Amsterdam. De Boelelaan 1085, 1081 HV Amsterdam, the Netherlands.

Wouter P.C. Boon. Copernicus Institute of Sustainable Development. Utrecht University. Heidelberglaan 2, 3584 CS Utrecht, the Netherlands.

Jacqueline E.W. Broerse. Athena Institute for Research on Innovation and Communication in Health and Life Sciences. VU University Amsterdam. De Boelelaan 1085, 1081 HV Amsterdam, the Netherlands.

Corresponding author: Marlous E. Arentshorst. T: 0031 (0)20 59862 71. F. 0031 (0)20 598 7027. E. m.e.arentshorst@outlook.com

Please cite as: Arentshorst, M. E., de Cock Buning, T., Boon, W. P., \& Broerse, J. E. (2015). Prospecting responsible technology paths: Management options for an appropriate societal embedding of medical neuroimaging. Science and Public Policy, 42 (6): 775-788.

doi:10.1093/scipol/scv004 


\begin{abstract}
Responsible innovation implies an aligment of what developers and societal actors perceive as problems and purposes fulfilled by new technologies. With this, the challenge is to prospectively identify potential concerns and (systemic) barriers that might hamper innovation development and embedding. We address this challenge by contextualising different visions of medical neuroimaging, which we identified via interviews and focus groups. We show that different visions result in different desirable technology paths, each with specific concerns and barriers. Concerns include medicalisation and the burden of knowing a predisposition. Barriers comprise scientific unknowns, technical impossibilities, disciplinary boundaries and the focus on disease categories and cure in research and health practice. Proposed strategies to overcome the barriers include different research incentives; training of scientists and health professionals and the development of person-centred health centres. We conclude with implications for the responsible management of medical neuroimaging, in which shared visions and mutual learning are key-elements.
\end{abstract}

Keywords: Responsible research and innovation, Neuroimaging, Emerging technologies, Constructive technology assessment, Vision assessment, Technological paths 


\section{Introduction}

During the emergence of technological novelties, socio-institutional embedding and the technology itself co-evolve (Nelson and Winter, 1982; Bijker et al., 1987). The development of an innovation is therefore dependent on interrelated dynamics and mechanisms, such as articulation of demands, networks and technologies. In this regard, it is important to take societal demands and concerns into account, as the failure of innovations such as genetically modified foods and crops in Europe and the subsoil $\mathrm{CO}_{2-}$ storage in the Netherlands signified (e.g. Chilvers and Macnaghten, 2011; ESRC, 1999).

Taking into account these various forces during technology development should lead to innovations targeting the creation of societal benefits, including economic growth, and also the management of negative side effects of innovations on society and the natural environment. This perspective on technology development and innovation processes is increasingly referred to as responsible innovation or responsible research and innovation (RRI). Von Schomberg (2012, p.9) defines RRI as:

... a transparent, interactive process by which societal actors and innovators become mutually responsive to each other with a view to the (ethical) acceptability, sustainability and societal desirability of the innovation process and its marketable products (in order to allow a proper embedding of scientific and technological advances in our society).

Stilgoe et al (2013, p. 1570) take a broader perspective by indicating that it:

... means taking care of the future through collective stewardship of science and innovation in the present.

Managing innovation trajectories to facilitate an appropriate societal embedding is not a new phenomenon and diverse approaches incorporate RRI-related concepts, such as better foresight, more responsive and adaptive governance and public engagement, aiming to manage innovation process and open them to societal influence (Owen and Goldberg 2010). Constructive technology assessment (CTA) is an example of such an approach and aims to learn about potential positive and negative impacts posed by a wide range of actors (Rip et al., 1995). CTA has a long history in aiming for technologies that connect better with societal practices, has already been operationalised, and implemented in practice since the late 1980s (e.g. Broerse, 1998; Broerse, et al., 2009; Rip et al, 1995; Roelofsen, 2011; van Merkerk, 2007). In this article the focus is on CTA as an approach to RRI (see section 3). 
Applying approaches to RRI in an early phase of innovation development is expected to lead to an improved translation of the innovation and to facilitate its embedding in society (Wilsdon and Willis, 2004; Rogers-Hayden and Pidgeon, 2007; Roelofsen, 2011). Research on CTA indicates that approaches aiming at an optimum balance between desirable positive and undesirable negative impacts of innovations can add value to emerging and ongoing research and to reflection on research agendas (e.g. Rip, 2009, Roelofsen, 2011). However, the subsequent responses of actors are generally disappointing (Rip, 2009; Roelofsen, 2011; Schuurbiers and Fisher, 2009). Although actors come to new insights and are stimulated to establish new spin-offs and adjust their research agenda, realisation of these intentions most often fails. One reason offered in evaluations of these approaches is that the intentions do not comply with the dominant culture (thinking), structure (organising) and practice (doing) that form the socio-technical regime (Geels, 2004; Roelofsen, 2011). Changing the dominant regime is complex given its resilience to change. For example, Kloet et al. (2013) showed how activities of actors in a multi-actor, innovationcentred consortium were constrained by formal and informal rules, regulations and procedures of the socio-technical regime. By understanding the mechanisms of the socio-technical regime, barriers that hinder the development and implementation of desirable applications can be identified, explained and, potentially, managed.

To deal with barriers imposed by the incumbent regime and to contextualise the ideas and visions around an emerging technology, RRI implies the challenge of prospectively identifying potential concerns and (systemic) barriers that might hamper the development and embedding of emerging science and technology. Such a RRI process might lead to innovations in the direction that is perceived by relevant actors as desirable. In light with the need for better understanding the way in which emerging technologies like medical neuroimaging innovations can be responsibly positioned vis-à-vis the incumbent regime, we took the challenge of prospectively identifying potential concerns and (systemic) barriers that might hamper development and embedding by operationalising CTA as an approach to RRI.

This paper addresses this challenge focusing on neuroimaging innovations in the Dutch clinical context as an example of an emerging technology with potential benefits and negative effects. Innovations in neuroimaging make it possible to visualise and study the function, connectivity, activity and biochemistry of the brain as an intact structure, e.g. including functional Magnetic Resonance Imaging (fMRI), Positron Emission Tomography (PET), Electro Encephalogram (EEG) and Magneto-encephalography (MEG). To date, these technologies have contributed to insights into neural processes associated with three major type of disorders: psychiatric (e.g. Malhi and Lagopoulos, 2007), behavioural (e.g. Dickstein, et al., , 2006) degenerative (e.g. Rosas et al., 2004) brain disorders. Moreover, neuroimaging technologies have 
contributed to improved diagnosis and therapies for some of these disorders. They are primarily embedded in secondary care, i.e. hospitals, and applied to diagnose brain disorders and, to a lesser extent, assist in the treatment of some of these disorders. Technological advances, such as increased spatial and temporal resolution and improved options for data-analysis, are expected to result in more detailed views of specific regions of the brain. This should lead to increased understanding of both the brain and the

origin and development of brain disorders. These technological advances and resulting knowledge are expected to lead to the development of improved diagnosis and treatment options and to contribute to novel options for prevention (e.g. Ewers et al., 2011; Szymanski et al., 2010; Willmann et al., 2008). Negative effects include the growing knowledge of the brain that may further extend the boundaries defining illness or redefining problems as medical conditions (medicalisation), and thereby increase the demand for medical services. People who do not display any symptoms may not want to know that they have a subclinical brain disorder, especially in the absence of an effective treatment (e.g. Fuchs, 2006; Glannon, 2006; Illes and Racine, 2005). Both positive and negative impacts of neuroimaging are uncertain in the current early phase of development.

In this article we address the challenge of prospectively identifying concerns and (systemic) barriers that might hamper development and embedding of medical neuroimaging by contextualising identified visions of actors related to these developments in the Netherlands and explore how these visions are embedded in the norms and values of the broader innovation community. The aim is to deduce factors, mechanisms and dynamics which might become barriers during the development of neuroimaging innovations, by this adding to the understanding of how to formulate strategies to manage medical neuroimaging in a responsible way.

\section{Towards prospective responsible technology paths}

Early phases of innovation development are characterised by uncertainty regarding which developments will be realised, what knowledge will be generated, what artefacts are to be developed, and what societal impacts these might have. In this phase, technology developers may hold different visions (or beliefs) about "what is feasible or at least worth attempting” (Nelson and Winter, 1982, p. 258). This leads them to follow different paths of innovation development (Garud and Rappa, 1994). During development, specific technological competencies, such as the form and function of the artefact, are articulated. Technology developers within a group share perceptions of an attainable future and shape the future of technical artefacts with their ideas, through which a script of expected user behaviour is materialised in the artefacts (Akrich, 1992). These perceptions and scripts function as a 'language' that guides actions in 
concrete practices of technology development and are called 'guiding visions' (Grin and Grunwald, 2000).

Guiding visions are not developed in isolation: the technology becomes institutionalised in a community of developers (Garud and Rappa, 1994). Technology developers in the same group, who share certain guiding visions, also share the same rules, routines, and structures for evaluation of the technology resulting in a specific technology path (Garud and Rappa, 1994); or technological trajectory (Dosi, 1982). Technology developers tend to commit themselves to this technology path, becoming path dependent. Data consistent with the practices of the group are perceived as information and data inconsistent with the practices of the group are sometimes ignored or perceived as noise (Geels, 2004). This is not a linear process, as pointed out by Garud and Rappa (1994); it is a process in which there is a reciprocal interaction between the beliefs or guiding visions of a technology developer ('what is possible'), the technical artefacts they create (form and script or functional use of technology) and the evaluation routines they promote (testing routines and normative values).

Garud and Karnøe (2001) introduced the notion of 'path creation', which connects path dependence with studying alternative routes for technology development. The process of path creation includes deliberate or mindful reflection on possibilities for diverting from the existing path. The notion of path creation highlights that the actions of actors have consequences for the paths that are in the making. In this way, actors influence path creation in a real-time manner. Understanding of the process of technology evolution could thus provide options to manage an innovation in early phases of development.

When studying these prospective technology paths, the three interrelated elements of Garud and Rappa's socio-cognitive model of technology evolution also play a role. In this context, visions about the technology serve as a proxy for the beliefs about potential future artefacts. These visions explicitly leave room for reflexivity, thereby extending an actor's scope and evaluation criteria. The function of visions is to "deliver orientation for present acting and deciding” (Grin and Grunwald 2000, p. 179). In other words, long-term considerations of future expectations are used to orient present actions, including those that influence technology development. Understanding these long-term orientations offers opportunities to identify emerging technological paths that are deployed by innovation developers. By identifying the visions of other relevant actors, it also offers possibilities to divert from these paths or to create alternative paths. In turn, identification and combination of individual visions of relevant actors offers opportunities to construct a more balanced, shared vision (Grin and Grunwald, 2000), which serves as a signpost for a more responsible technology path. 
In addition, technology paths are influenced by external factors (e.g. Geels, 2004), such as an increase in the number of chronically ill patients, the economic crisis and innovative initiatives. A system perspective provides understanding of the mechanisms and dynamics of the socio-technical regime and facilitates an analysis of potential systemic barriers hampering the innovation development and embedding (Kloet et al., 2013). This provides understanding of whether activities of actors are indeed imposed by barriers of the incumbent regime, and if the strategies proposed to overcome the barriers take into account the dominant structures and practices of the system.

\section{Method}

\subsection{Approach}

To operationalise CTA as an approach to RRI, we use the Interactive Learning and Action (ILA) model (Broerse and Bunders, 2000), combined with Vision Assessment (Grin and Grunwald, 2000). Roelofsen et al. (2008) showed that the combination of these two approaches results in an approach which is suitable for analysis of and intervention with emerging technologies in the field of ecogenomics. We build upon these insights and apply this approach combined with a system perspective (e.g. Geels, 2004) to assess medical neuroimaging technologies. The approach is characterized by an emergent and flexible design. Key features of the ILA model (Broerse and Bunders, 2000) are: encouragement of active participation of all relevant actors, early in the process and on an equal footing; explicit acknowledgment of experiential knowledge; development of shared visions; knowledge creation through mutual learning (via dialogue); enhancement of trust relationships; coalition building; and independent and competent process facilitation. With vision assessment, shared future visions can be shaped that guide the directions of technology development (Grin and Grunwald, 2000). Elements central to the identification and construction of visions (Grin and Grunwald, 2000; Roelofsen, 2011) include:

- Problem definition: different visions can entail various problem definitions and ways to assess solutions. Assessing the assumptions underlying a problem definition uncovers values and norms of how actors look upon reality, perceive facts and define the problem.

- Challenges and purposes to be fulfilled: this element concerns the challenges and purposes to be fulfilled, resulting from the specific practice of which actors are part. The problem definition contextually vindicates the challenges and purposes to be fulfilled.

- Relevant contextual aspects: this element explores the relation between the technical artefact and contextual aspects. Examples include the context in which the artefact will be 
used, how and by whom (e.g. conditions under which the technical artefact may contribute to solving a problem), who will benefit and who will possibly experience disadvantages. These elements also include factors that may hamper the realisation of the envisaged technical artefacts, namely barriers that need to be overcome.

- Basic features of the desirable state: this element refers to basic assumptions around which visions develop: the preferred state of affairs the vision entails and ideas about what the world should look like.

This combined approach gave us the opportunity to identify those visions of neuroimaging from different relevant actors which related directly to the aims of our research, described above.

\subsection{Research design: identification of neuroimaging visions}

To identify vision of neuroimaging from different relevant actors (see box 1 for an overview), we started with the identification of future neuroimaging technology paths and potential resulting artefacts. Hereto we made an inventory of guiding visions from a neuroimaging developers' perspective, including scientists and industrial producers, because these developers currently shape future directions of neuroimaging with their beliefs and ideas (Akrich, 1992; Garud and Rappa, 1994; Grin and Grunwald, 2000; Roelofsen et al., 2010). Therefore we conducted and analysed semi-structured interviews ( $\mathrm{n}=17)$ and four focus groups with industrial producers technology developers and scientists $(n=19)$ (details in Arentshorst et al., 2014). We recruited respondents using the degree of having specific expertise and experience as an individual representing an actor group as selection criteria. During the entire process we challenged the interviewees and focus group participants to propose other relevant actors who were expected to be affected (positively or negatively) by neuroimaging. These actors were taken as a starting point for the next phase of the research. Subsequently, such 'snowball exercise' of respondent recruitment was applied to identify and consult other actors and ended when referrals did not result in new suggestions. As a next phase of our research we identified and constructed visions of potential relevant societal actors. For this purpose we interviewed 5 policy-makers, 8 health professionals and 3 representatives of patients. In addition, six focus groups with Dutch citizens $(n=46)$ were organised to analyse public perceptions of medical neuroimaging. Next, we organised a multi-stakeholder dialogue meeting with scientists, industrial producers, policy-makers and health professionals $(n=17$,) to raise awareness of the different visions of neuroimaging and to validate and discuss our results. Subsequently, questionnaires were used to identify actions undertaken as result of the dialogue meeting (details in Arentshorst et al, 2014; 2016). 
As a consequence of the early phase of neuroimaging development, we consulted those actors who are most interested in new scientific and technological developments. These actors were capable of disembedding from existing structures, i.e. mindful deviation (Garud and Karnøe, 2001). Therefore they might be classified as pioneers, and it is likely that the views presented in this article do not correspond with the views of other actors in the same field. However, pioneers, in contrast to their fellow regime actors, are the most likely ones to take up the challenge of establishing the changes they perceive as necessary in the health system when options to do so become available. They might thus influence the future views and practice of actors in the same field and mobilize a collective, despite resistance and inertia (Garud and Karnøe, 2001). They therefore seem to be the best selection for this study. Although our study might not encompass all potential visions, we did obtain saturation regarding articulated desirable artefacts and barriers, meaning that we only stopped interviewing different actors when we received no new information. The barriers related to the three different visions of neuroimaging have been validated by the respondents in our study as important elements in managing, prospectively, neuroimaging developments towards more responsible artefacts, including their responsible societal embedding. 


\section{Box 1. Actor field of medical neuroimaging}

We distinguish the following different actor groups which have their own structure, culture and practice and share structures with other groups forming together the wider societal health system:

- Scientists: actors who work with neuroimaging technologies or knowledge resulting from neuroimaging applications in a research setting.

- Industrial producers: actors who produce neuroimaging technologies. These actors may be concerned with technical standards and functional requirements.

- (Potential) future users

o Receivers: actors who undergo neuroimaging, e.g. patients.

o Appliers: actors who apply neuroimaging in clinical practice or use the knowledge resulting from these technologies, e.g. health professionals. Within this group we distinguish the following health professionals based on the current organisation of the health system and differences in structures and practice on a more detailed level:

- Professionals working in primary care

- Professionals working in secondary care

- Professionals working in the field of somatic disorders

- Professionals working in the field of mental disorders

o Host institutions: actors of neuroimaging companies and institutions in which neuroimaging equipment is located, including hospitals and private imaging institutes, who deal with liability and how to apply these technologies.

- Policy-makers: actors who deal with rules concerning administrative regulations and procedures which structure the health system. For example, regulations regarding the application of technologies, safety standards, and reimbursement regulations.

- Citizens: actors who might use or are affected by neuroimaging in the future, but are not part of the health system. In contrast to the actors described above, the perceptions of citizens are based on a personal perspective rather than a professional one. Their knowledge can be considered as 'contributory expertise' (Collins and Evans, 2002) and their desires, demands and concerns should also be taken into account in an early phase of innovation research and development in order to maximise the potential benefits of innovations for users of the future.

Interviews, focus groups and the dialogue meeting were audio-recorded and interviews and focus groups were transcribed verbatim for further analysis. Summaries of the interviews and focus groups were returned to the respondents with the request to check whether the summary was complete and interpretations made were correct. The identities of the respondents were anonymised by replacing their name with unique research codes. Subsequently, data was analysed with qualitative data analysis software (ATLAS.ti). In this analysis we focused on the identification of elements regarded as important in vision 
assessment: problem definition, challenge and purposes to be fulfilled, relevant contextual aspects and basic features of the desirable state. New sub-elements were noted as they became apparent in the data (Grin and Grunwald, 2000; Roelofsen et al., 2008).

To gain understanding of challenges and barriers that might become obstacles when neuroimaging is further developed, we made use of the multi-level perspective (MLP) (e.g. Geels, 2004; Loorbach, 2007). The MLP is a heuristic tool to analyse dynamics of socio-technical changes. Three interrelated analytical level are distinguished: the landscape level (the exogenous and slow-changing landscape), the regime level (communities of interacting groups with dominant cultures, structures and practices) and the niche level (small-scale innovative initiatives). Placing our results in this framework allowed a contextualised analysis of the concerns and (systemic) barriers articulated from a system perspective. In the next section we describe identified concerns and barriers that might become obstacles when neuroimaging is further developed, followed by strategies described by the respondents as to how to manage these. With this, we integrate the results of previous phases of our research (see section 3.2), and as a result make a distinction between visions of a) neuroimaging developers, comprising scientists and industrial producers, b) societal actors, comprising health professionals, policy-makers and patient representatives, and c) citizens.

\section{Concerns and barriers that might complicate or hamper neuroimaging development and embedding}

Desirable neuroimaging applications from a developer's perspective focus on new and improved options for the prevention, diagnosis and treatment of brain disorders. All health professionals, policy-makers, patient representatives and citizens consulted envision the formulated neuroimaging options from a developer's perspective in itself as conditionally desirable as well (details in Arentshorst et al, 2014). But what about concerns and barriers related to the envisioned desirable embedding of these neuroimaging applications in practice? In the next section we contextualise the identified visions of respondents and explore concerns and factors, mechanisms and dynamics which might become barriers during the development of neuroimaging innovations.

\subsection{General concerns and undesirable neuroimaging paths}

All respondents raised concerns related to the enhancement of 'healthy' people, which potentially results in questioning what is normal and healthy. With this, they expressed fear of medicalisation of relatively healthy people. Furthermore, some citizens, patient representatives, health professionals and policy- 
makers expressed concerns regarding the burden of frequent monitoring with respect to time and the challenge of confronting the finiteness of life. In addition, some citizens and patient representatives articulated concerns regarding the potential harmfulness of frequent neuroimaging use and a shift from testing medication on animals towards the acceptance of humans as test objects, by for example neuroimaging possibilities to monitor the effectiveness of medication in the brain. Furthermore, all respondents expressed concerns regarding potential negative social and economic implications that an early diagnosis or indication of predisposition can cause. This could result in unethical and therefore undesirable use of neuroimaging artefacts, for example stigmatisation and discrimination caused by use and abuse of neuroimaging data by commercial parties, such as insurance companies and mortgage lenders. Many citizens also found the use of neuroimaging to search for additional disorders, life styles and sexual preferences undesirable. Additionally, they expressed their fear of the reduction of a person to a mere 'image', excluding experiences of health professionals, patients and nurture factors from the diagnostic and treatment process.

Concerning the use of neuroimaging to determine a predisposition, the uncertainty the predisposition represents, in terms of the chances of developing a disorder, and the burden of knowing were articulated as disadvantages of this artefact by all respondents, especially when there is no treatment available. All neuroimaging developers, representatives of patients, secondary care professionals and some of the citizens and policy-makers consulted were concerned that large scale preventive neuroimaging use might be expensive in terms of personnel and follow-up action and thus jeopardise the overall affordability and accessibility of health care.

Some health professionals, policy-makers, patient representatives and citizens expressed concerns regarding rules and regulations. On the one hand, they argued that rules and regulations often develop slowly, potentially resulting in applications being applied too early in ways that might turn out to be risky or unethical. For example, the Dutch law states that citizens with a genetic burden cannot be excluded from health insurance. However, it is still possible to reward a symptomless group of people, which can lead to a financial disadvantage for those with a genetic burden or chronic disorder. As neuroimaging might give more insight into who has a predisposition or a disorder at an early stage, some of them expect that health insurance companies will increasingly explore these kind of 'rewarding' options. They argue that the law should be adjusted before neuroimaging applications make this option possible. On the other hand, rules and regulations were by some health professionals and neuroimaging developers perceived to hamper full exploitation of neuroimaging possibilities. An example is the European directive on the "minimum health and safety requirements regarding the exposure of workers to the risks arising from 
physical agents (electromagnetic fields)" ${ }^{1}$. This directive, which is not yet implemented, addresses the protection of workers exposed to electromagnetic fields by setting a limit to the exposure of electromagnetic fields. However, the proposed maximum exposure for people working with MRI techniques is so low that making a MRI scan might no longer be possible.

The majority of the consulted developers (both scientists and industrial producers) were concerned about the management of expectations around neuroimaging innovations, which they perceived as a potential barrier. Also some of the health professionals, policy-makers and patient representatives consulted suggested the insufficient and/or exaggerated communication to the general public of the possibilities of neuroimaging as a concern. For example, claiming that many or all disorders and behaviours are located in the brain, which can be 'fixed' when there is something 'wrong', is an oversimplification. Communication of such a message towards the general public is expected to result in inevitable disillusion. The more science gives society the idea that 'they' know what is wrong and how it can be 'fixed', the more this will result in demands from society that science has to solve its problems. Neuroimaging developers considered misconceptions of neuroimaging by the general public as a barrier that could lead -over time- to disillusion and the rejection of neuroimaging technologies.

The concerns are summarized in Table 1.

Table 1. Formulated concerns and articulated strategies to overcome these.

\begin{tabular}{|c|c|c|c|}
\hline Vision & Concern & Strategy & Result strategy \\
\hline $1,2,3$ & $\begin{array}{l}\text { - Enhancement and medicalisation } \\
\text { of 'healthy' people Harmfulness } \\
\text { and burden of frequent } \\
\text { neuroimaging use } \\
\text { - Negative social and economic } \\
\text { implications } \\
\text { - Reduction of a person to a mere } \\
\text { 'image' } \\
\text { - Burden of knowing predisposition } \\
\text { - Overall affordability and } \\
\text { accessibility of health care when } \\
\text { preventive neuroimaging } \\
\text { applications are applied on a large } \\
\text { scale } \\
\text { - Slow development and hampering } \\
\text { aspects of rules and regulations } \\
\text { Management of expectations }\end{array}$ & $\begin{array}{l}\text { Setting boundaries and rules for } \\
\text { neuroimaging use. The actor that is } \\
\text { considered as the prime mover here } \\
\text { is primarily the government. } \\
\text { Information dissemination } \\
\text { - Provision of information to } \\
\text { individuals/patients, e.g. } \\
\text { regarding available options, } \\
\text { reliability of tests, potential } \\
\text { damage and consequences, etc. } \\
\text { - Provision of 'correct' information } \\
\text { by the government and scientists } \\
\text { to health professionals and the } \\
\text { general public about the } \\
\text { possibilities and limitations of } \\
\text { neuroimaging. }\end{array}$ & $\begin{array}{l}\text { Reduction of concerns } \\
\text { Appropriate societal } \\
\text { embedding of } \\
\text { neuroimaging } \\
\text { applications }\end{array}$ \\
\hline
\end{tabular}

\footnotetext{
${ }^{1}$ www.ec.europa.eu. Directive 2004/40/EC, directive 2008/46/EC and directive 2012/11/EU
} 


\subsection{From different desirable neuroimaging paths to different barriers to solve}

Although all respondents envision neuroimaging applications to realise new and improved options for prevention, diagnosis and treatment as desirable, the desirable contextual aspects of potential applications and underlying basis features of the desirable state are perceived differently. In other words, the technical artefacts in itself are considered desirable, but the envisioned embedding in practice differs. We identified and constructed from interviews and focus group data, three different visions on how actors relate neuroimaging to the health system. Neuroimaging technologies are envisioned in 1) the current health care practice, 2) personalised health care and 3) person-centred health centres (see Box 2).

Box 2. Three visions how actors relate neuroimaging to the health system

Vision 1: Neuroimaging in the current health care practice

In this vision, neuroimaging technologies are affordable and able to visualise brain disorders at a sub-disorder and/or individual level. Their appearance is not that different from current neuroimaging technologies, i.e. mostly large equipment located in hospitals. Applications make improved prevention, diagnosis and treatment of brain disorders possible and are perceived as embedded in the current structures and practices of the health system in order to optimise it.

Vision 2: Neuroimaging in personalised health care

In this vision, neuroimaging applications are affordable and able to visualise disorders at an individual level, i.e. person-centred applications. The purposes to be fulfilled by the neuroimaging applications correspond with vision 1, i.e. improved prevention diagnosis and treatment of brain disorders. In this vision, neuroimaging applications are envisioned to be embedded in a person-centred health system. Embedding is envisioned in primary and secondary care and/or in a new in-between setting; e.g. 'one and a half care', as long as the structure and practice facilitates personalised care.

Vision 3: Neuroimaging in person-centred health centres

In this vision, neuroimaging applications are affordable, compact, mobile and able to visualise disorders at an individual level. The neuroimaging applications are primarily embedded at health centres, at primary care level. The purposes to be fulfilled by the applications correspond with the previous two visions, i.e. individual prevention and (more) personalised diagnosis and treatment. In addition, respondents holding this vision have the purpose to apply collective prevention strategies, e.g. the screening of symptomless people.

In vision 1, the technical optimisation of preventive, diagnostic and treatment tools is considered to optimise the structures and practices of the health system and hence contribute to a better health system in general. In addition to this technical optimisation, visions 2 and 3 imply structural changes in the structures and practice of the health system and, through this a better health system in general. In other words, the challenges and purposes to be fulfilled, contextual aspects, and underlying basic features of the desirable state differs, resulting in different visions of neuroimaging. In a previous phase of our research we concluded that our results indicate that the visions of neuroimaging are not exclusively related to a specific actor group, such as policy-makers or primary care professionals. We observed that the position a respondent has in the health system and the vision he or she has of the ideal health system (which are interrelated) drives the vision of neuroimaging an actor holds. As a result, desirable neuroimaging 
applications are envisioned in a way that they maintain or increase the position of a respondent, and suit his/her vision of the ideal health system and/or contribute to establish this ideal health system, resulting in different desirable technical artefacts (for example large device in hospital versus mobile device in health centre) and related technology paths. Different technology paths to establish neuroimaging artefacts each have, in turn, specific barriers. The respondents who envision neuroimaging in the current health care practice (vision 1), formulated most of their challenges and barriers on a technological and knowledge level. Various respondents holding this vision identified additionally barriers intrinsic to the dominant science regime. Respondents who envision neuroimaging in personalised health care (vision 2), and respondents who envision neuroimaging in person-centred health centres (vision 3), articulated, besides aforementioned challenges and barriers, challenges and barriers related to the way in which health care is provided.

\subsection{Knowledge and technological barriers}

Identified barriers focus on scientific knowledge, which is not yet sufficient to establish desirable neuroimaging artefacts, and the high costs and time-consuming aspects of scientific research. Related are the technological barriers, such as temporal and spatial resolution, the large size of neuroimaging technologies and differences between scan results (both differences in devices and methods and between individuals), which need to be improved in order to realise the desired neuroimaging artefacts. An example of a knowledge problem is the difficulty of differentiating between a healthy and a non-healthy brain at individual level. In this case, differences are currently only visible when large groups are compared, or when one individual is followed over time, being its own control with respect to interventions with medicine or otherwise.

Some of the neuroimaging developers, policy-makers and health professionals consulted saw these barriers only from the perspective that they are obstacles that need to be conquered, whereupon the neuroimaging artefact can be developed and subsequently embedded in the health system. As explained by one of the scientists:

We are constantly trying to improve our cognitive capacity, but there are probably ways to do that psycho-pharmacologically at some point. If we have the knowledge then we can improve memory and know what kind of pills we can administer to establish that.

However, other respondents argued that knowledge and technological barriers are the result of barriers intrinsic to the science regime. They warned against the focus on a specific (part of a) disorder in the current science regime, resulting in fragmentation of scientific research and subsequent tunnel vision of 
researchers. This structure hinders the exploration and study of relations between disease categories, resulting in parallel research activities, which might be unnecessary when, for example, the underlying disease mechanisms are similar. Moreover, answers (knowledge) and options resulting from crossfertilisation activities, which might be beneficial for both research activities and clinical practice, might be missed.

Furthermore, structures regarding scientific validity, i.e. rules regarding scientific evidence, are perceived as a barrier. The current 'golden standard' hampers research into possible subtypes of a disorder because this implies working with smaller, more specific groups for which the criteria to set up the groups are unknown. As a result, research into subtypes would imply a loss of statistical power and consequently more expensive research (cf. research into rare diseases and personalised medicine). As explained by one of the health professionals working in the field of mental disorders:

Even in the new DSM [Diagnostic and Statistical Manual of Mental Disorders] that distinction [between different types of depression] is still not made. I think there is a kind of dogmatism in the research that maintains itself. [...] People have to let go of certain ideas of doing research in a particular way and establish a new approach in which interactions between certain vulnerabilities, gene level, personality level and certain environmental variables have a central place. That is, of course, much more difficult because you need huge numbers of people. So I think in terms of costs, the research as it happens is a lot cheaper. If you break down those groups, subdivide them, then you lose evidence / statistical power. So then you need to have larger groups, which costs more money.

In addition, some of the developers and many of the health professionals, policy-makers and patient representatives consulted saw the disciplinary boundaries of the science system as a barrier. This barrier constrains the realisation of interdisciplinary research, which is considered necessary to advance the field. They perceived the scientific regime as rigid with its own dynamics, in which many scientists strive for personal gain and status. This barrier is partly seen as related to professional and financial structures, but it is also related to the reluctance of scientists to cooperate with other actors, both academics as well as non-academics. Paramedic professionals, for example, still face a huge struggle in becoming a partner in scientific research, because their research centres are connected to higher vocational rather than academic institutes. Many of the neuroimaging developers consulted argued that interdisciplinary research, although necessary, is expensive and time-consuming, which serves as a barrier to conduct this type of research. Moreover, interdisciplinary research is considered not to be 'rewarding'. This is related to the 
lack of suitable journals that publish results from interdisciplinary research and the lower impact factors these journals have, which constraints career advancement.

\subsection{Barriers intrinsic to the structures and practices of the health system}

Respondents visioning neuroimaging in personalised health care (vision 2) and in person-centred health centres (vision 3), additionally described barriers related to the structures and practices of the health system. These barriers arise from criticism towards the current focus on disease categories in health care practice and focus primarily on the practice through which health care is provided. Respondents explained that many health professionals diagnose and treat diseases per category and hence focus on the disorder a patient has rather than on the patient who has a disorder. According to them, such a focus results in the barrier of a limited vision on the illness and health of the patient in question and, as a consequence, in case of co-morbidity, in the provision of contradictory cure and care options to the patient by different disciplinary experts. As explained by a representative of primary care professionals:

People often do not have a disorder, you deal with multi-morbidity [...] What matters is: what is wrong with this person? So not disease-specific and resulting conflicting advice, medication, etcetera. One should look at the whole person.

In addition, some health professionals, policy-makers and patient representatives described the barrier of patients feeling that they have no say in their diagnosis and treatment trajectory. This results, for example, in non-compliance and a passive attitude, because patients are not offered options to become responsible for their own health and recovery. Furthermore, the distinction that is still made by medical professionals, patients and society in general, between somatic and mental disorders was articulated as a barrier by many of the health professionals, policy-makers and patient representatives consulted. Somatic disorders (for example neurological disorders) are perceived as 'real' disorders and mental disorders (for example depression or anxiety disorders) are at least envisioned as 'not that real'. This results according to these respondents in a view of respectively, patients who have a disorder and those who have complaints, and medical professionals who deserve more respect and status than others. As explained by a health professional working in secondary care in the field of mental disorders:

I think that the professionals have to communicate that more clearly [that a mental disorder is also a disease]. The problem is that many colleagues, and somatic professionals in particular, envision to some extent that psychiatry is also a bit of a trifle thing. 
Furthermore, respondents holding the vision of neuroimaging in person-centred health centres (vision 3), articulated the barrier that the focus of the health system is too much on cure, hampering the prevention of disorders and resulting in a distinction between primary and secondary care. As explained by one of the policy makers:

... from care and illness to health and behaviour. First things first: Earlier! Quicker! Better! Then you need diagnostics and also screening.

The barriers and formulated strategies to overcome these are summarized in Table 2 .

Table 2. Formulated barriers and articulated strategies to overcome these

\begin{tabular}{|c|c|c|c|}
\hline Vision & Barrier & Strategy & Result strategy \\
\hline \multicolumn{4}{|c|}{ Knowledge and technological barriers } \\
\hline $1,2,3$ & $\begin{array}{l}\text { - } \text { Scientific unknowns } \\
\text { - } \quad \text { Technological impossibilities }\end{array}$ & $\begin{array}{l}\text { - More funding } \\
\text { - Public-private partnerships }\end{array}$ & $\begin{array}{l}\text { More research } \\
\text { Neuroimaging } \\
\text { technological } \\
\text { breakthroughs }\end{array}$ \\
\hline \multirow[t]{2}{*}{$\begin{array}{l}(1), 2, \\
3\end{array}$} & $\begin{array}{l}\text { Barriers intrinsic to the science } \\
\text { regime } \\
\text { o Focus on disorders } \\
\text { o Disciplinary boundaries of } \\
\text { the science regime }\end{array}$ & $\begin{array}{l}\text { - Change incentive structures to favour } \\
\text { research: } \\
\text { o Interdisciplinary research as a } \\
\text { prerequisite for funding } \\
\text { o Interdisciplinary journals with } \\
\text { high impact factor } \\
\text { - Education of scientists }\end{array}$ & $\begin{array}{l}\text { More person-centred, } \\
\text { interdisciplinary } \\
\text { structure and practice of } \\
\text { research }\end{array}$ \\
\hline & o Scientific validity & $\begin{array}{l}\text { - Development of statistical tests for } \\
\text { small populations in relation to health } \\
\text { risks for that population }\end{array}$ & $\begin{array}{l}\text { Scientific evidence } \\
\text { based on } n=1\end{array}$ \\
\hline \multicolumn{4}{|c|}{ Barriers intrinsic to the structures and practices of the health system } \\
\hline \multirow[t]{2}{*}{2,3} & $\begin{array}{l}\text { - Focus on disease categories } \\
\text { o Distinction between somatic } \\
\text { and mental disorders }\end{array}$ & $\begin{array}{l}\text { - Development of integrated cure and } \\
\text { care plans and implementation in } \\
\text { interdisciplinary teams } \\
\text { - Education of professionals to perform } \\
\text { new and different tasks in person- } \\
\text { centred context } \\
\text { - New categories of professionals to } \\
\text { apply and interpret neuroimaging in } \\
\text { person-centred context }\end{array}$ & \multirow[t]{2}{*}{$\begin{array}{l}\text { Person-centred, } \\
\text { integrated health care }\end{array}$} \\
\hline & $\begin{array}{l}\text { - Patients no say in diagnosis and } \\
\text { treatment }\end{array}$ & $\begin{array}{l}\text { - Implementation of shared-decision } \\
\text { making }\end{array}$ & \\
\hline
\end{tabular}




\begin{tabular}{|l|l|l|l|}
\hline 3 & $\begin{array}{l}\text { - Clinical focus on cure } \\
\text { o Distinction between } \\
\text { prevention and cure \& care } \\
\text { o Distinction between primary } \\
\text { and secondary care }\end{array}$ & $\begin{array}{l}\text { - New health institutions at primary } \\
\text { care level that are person-centred and } \\
\text { interdisciplinary } \\
\text { - Development and implementation of } \\
\text { self management options } \\
\text { - Include shift towards primary care } \\
\text { and self management in governmental } \\
\text { policies }\end{array}$ & $\begin{array}{l}\text { Health system with a } \\
\text { focus on prevention }\end{array}$ \\
$\begin{array}{l}\text { Shift from secondary to } \\
\text { primary care and self } \\
\text { management }\end{array}$ \\
\hline $\begin{array}{l}(1), 2, \\
3\end{array}$ & $\begin{array}{l}\text { Barriers intrinsic to the science } \\
\text { regime and structures and practices } \\
\text { of the health system }\end{array}$ & $\begin{array}{l}\text { - Networking } \\
\text { - Mutual learning }\end{array}$ & $\begin{array}{l}\text { Concerted effort to } \\
\text { realise different } \\
\text { structures and practices }\end{array}$ \\
\hline
\end{tabular}

\subsection{Management of concerns}

According to the majority of the respondents, most concerns can be managed by setting boundaries and rules for neuroimaging use. For example, they argued that neuroimaging can be limited to those brain disorders for which a predisposition can be identified and restrictions can be imposed on the use of data resulting from neuroimaging use outside the health system. Furthermore, according to health professionals, policy-makers, patient representatives and citizens consulted the concerns regarding the burden of knowing an early diagnosis and predisposition might be tackled by a) setting rules and boundaries relating to when and how these neuroimaging artefacts can be used and, b) providing individuals with information for a informed decision, such as available options, the reliability of the tests, potential damage and consequences in order to make a fully informed decision.

All neuroimaging developers consulted indicated that worries about unrealistic societal expectations can be reduced by providing the general public, including the government and health professionals with correct information about the possibilities and limitations of neuroimaging. They thought the government had a significant role in this process, but envisioned also a role for the scientific community

to correct 'false' stories and to provide information to citizens and end-users. The majority of the consulted citizens indicated that more information regarding the possibilities and limitations of neuroimaging, and medical technologies in general, would be appreciated. Several health professionals, policy-makers and patient representatives mentioned that information regarding the anticipated possibilities and meaning of neuroimaging artefacts (e.g. "what does it measure") might provide a clearer view on the possibilities and impossibilities of neuroimaging artefacts and prevent unrealistic expectations of medical professionals, patients and citizens. According to these respondents, the designated point of departure here is the science regime. 


\subsection{Management of barriers}

Knowledge and technological barriers. According to all respondents, the science regime will rise to the challenge to produce the required knowledge and will, together with industrial producers, establish ways to technologically improve neuroimaging technologies in order to eventually produce desirable neuroimaging artefacts, cf. public-private partnerships. At the same time, consulted health professionals, policy-makers, patient representatives and citizens emphasised that it is important that scientists and industrial producers become aware of perceived undesirable neuroimaging use and of concerns to promote the development of responsible innovations. In addition, financial support is required to overcome scientific unknowns and technological barriers, according to the majority of the respondents .

All respondents promoting a vision of neuroimaging in personalised health care (vision 2), in personcentred health centres (vision 3) and some respondents holding the vision of neuroimaging in the current health care practice (vision 1), considered that changes are necessary in the science regime to overcome knowledge and technological barriers. These respondents perceived the science regime as needing to adopt a different, disease transcending, interdisciplinary structure and practice of research. According to them, professional and financial structures should be changed in such a way that an interdisciplinary structure and practice of research becomes the new 'business-as-usual'. This includes the education of scientists to change their way of thinking and practice, and the incorporation of this new way of thinking in the educational programs of universities. The government and funding agencies are seen here as the designated point of departure, for example, by developing new funding strategies in which interdisciplinary research is a prerequisite for obtaining grants. Furthermore, many of them emphasised the importance of a change in structures with respect to 'scientific validity' and related 'rewarding' of interdisciplinary research. Structures, for example demands for statistical power, should change in order to make research into sub-types of disorders possible, rewarding and accepted as scientifically valid evidence. More investment should be made in the development and dissemination of statistical tests for small populations in relation to the health risks for that same population. Furthermore, the creation of interdisciplinary journals with high impact factors was a frequently articulated strategy, aimed at making interdisciplinary research more rewarding. They argued that this new culture, structure and practice would enable the research activities perceived as necessary to move from large patient groups to the individual level, i.e. studying the relations between disease categories, cross-fertilization studies and research into possible subtypes of a disorder.

Barriers intrinsic to the health system. According to respondents holding the vision of neuroimaging in personalised health care (vision 2) or in person-centred health centres (vision 3), overcoming the 
perceived barriers related to the health system requires a shift in structures and practices from a diseaseoriented towards a person-centred health system. These respondents argue that with this change, the advantages of neuroimaging possibilities can be fully exploited. They suggested that this can be accomplished by developing integrated cure and care plans and involving interdisciplinary teams, which have the consumer/client/patient at their heart. To this end, professionals need to be educated to perform new and different tasks in a person-centred context and hence change their professionals practice, i.e. behaviour, accordingly. New categories of professionals should be developed to apply and interpret neuroimaging in this context, and future patients should be encouraged to change their behaviour and to become responsible for their own health, through, for example, self-management options.

Respondents holding the vision of neuroimaging in person-centred health centres (vision 3) argued that, besides a shift towards a person-centred health system, a shift towards primary care and self-management is necessary. For this, a range of primary care professionals should be placed together in interdisciplinary health centres at primary care level. Respondents holding this vision argue that primary care should be the location where integrated care, including diagnostics, will start and, when appropriate, actors (professionals) from secondary care will be consulted or treat the patient. Moreover, self-management options should be offered to both patients and citizens to become responsible for their own health and, if necessary, for their recovery trajectory. The government is again perceived as the designated point of departure by pursuing these changes in their policies.

Dialogue meetings in which actors from different disciplines and regimes meet and learn from each other in a learning environment, might contribute to developing more shared desirable technology paths and applications, according to participants who attended our dialogue meeting. Participants of the dialogue meeting reported that the meeting resulted in greater awareness and exploration of potential barriers and new areas of innovation by discussing desirable and undesirable applications with actors outside their own practice. However, as indicated by the participants, actors from different disciplines and regimes do not normally make the effort to have a dialogue with each other. As suggested by the participants, these dialogues require facilitation in both bringing people together and in creating a safe environment where mutual learning may take place, and such interactions need to be organised with some regularity. 


\section{Conclusions and discussion}

\subsection{Conclusions}

In this study we explored concerns and barriers related to the development and embedding of neuroimaging in the Dutch health system from the points of view of different actors and by taking a system perspective. Our results show that all respondents have concerns related to the enhancement and medicalisation of 'healthy' people, the embedding of new preventive and diagnostic applications for which no therapeutic options exist yet, and the potential negative social and economic implications associated with preventive neuroimaging applications. Compared to neuroimaging developers, health professionals, policy-makers, patient representatives and citizens expressed more concerns about how neuroimaging may contribute to solving problems. This particularly applies to preventive neuroimaging use. According to many of the respondents, concerns can be managed when boundaries and rules are set for neuroimaging use and when sufficient and unbiased information is provided to those who undergo neuroimaging so that they can make a fully informed decision. With this they assume that when neuroimaging applications are well organised and there is proper information dissemination, concerns are 'managed' sufficiently. However, these strategies are traditional end-of-pipe policy tools of command and control with an underlying assumption that knowledge generates public acceptance of science and technology, and hence facilitates embedding of innovations (Druckman and Bolsen 2011, Nisbet and Goidel 2007). Previous research has shown that command and control measures and strategies to augment the knowledge of the general public neither result in a reduction of societal concerns nor increased public acceptance (e.g. Chilvers and Macnaghten, 2011; Hagendijk and Irwin, 2006; Marris et al., 2001). Concerns related to the potential harmfulness of frequent use of neuroimaging and the technical ability to determine the 'right' diagnosis, should therefore not be dismissed as a lack of scientific knowledge and/or as emotional concerns that can subsequently be addressed by information dissemination. Instead, these concerns should be taken seriously, for example via the interaction of different actors in dialogue, and be taken up in the technology development path.

This study shows which barriers need to be overcome in order to realise desirable neuroimaging applications. It demonstrates that different visions of neuroimaging result in different technology paths, which have their specific barriers. These barriers are cumulative and increase in number and complexity from vision one to three. Respondents holding the vision of neuroimaging in the current health care practice (vision 1) formulated most of their challenges and barriers on a technological, knowledge and financial level. These barriers are formulated by some developers, health professionals and policy-makers consulted from a point of view that they are obstacles that need to be conquered, whereupon the 
neuroimaging artefact can be developed and subsequently be embedded in the health system in order to optimise it. For other respondents, these barriers are also related to the incumbent science regime. Respondents holding the vision of neuroimaging in personalised health care (vision 2) and person-centred health centres (vision 3) additionally articulated barriers and challenges related to the health system. These barriers are formulated from a point of view that structural changes in the health care practice are needed in order to appropriately embed neuroimaging applications and with this establish a 'better' health system. In conclusion, many of the formulated barriers are indeed systemic in nature.

\subsection{Towards an appropriate societal embedding of medical neuroimaging}

We observed that the strategies articulated to overcome the barriers were formulated from within the professional practice of a respondent. They were envisioned to increase or maintain the position and/or status an actor has, while responsibility for the strategies was primarily handed to actors of other practices and regimes, preferably the government. In other words, actors protect and reinforce the rules of their regime (Geels, 2004). The strategies are formulated from the actors' perspective of the problem, without considering other actors' perspectives. These strategies might therefore fail due to their focus on the individual's own professional practice and their mismatch with the current structures and practices of the health system. In other words, although respondents identified barriers of systemic nature, their strategies to overcome these do not take the resilient system into account. On the other hand, there are potential destabilisers of the dominant regime. Landscape level trends, such as aging leading to more patients with brain disorders, and an increasing preference from citizens for having more control over one's own health (Jones 2008), combined with overcoming barriers by for example making it financially and technically possible to shift towards person-centred approaches and/or primary care, are potential destabilisers of the dominant regime. The findings above indicate that actors who envision neuroimaging in a health system with new structures and practices, might in this case start acting on changes they perceive as necessary. In that case, the incongruences in visions might be in conflict with each other.

In order to realise more responsible neuroimaging applications, actors need to make an effort to consider, understand and integrate the view of the other. To formulate strategies that take the resilience of the dominant system into account, the results of this research indicate that learning and understanding of the context from which barriers arise might result in strategies that are effective in overcoming the barriers (see for example the work of Regeer, 2010). Understanding of different visions of actors, including perceived barriers and strategies to overcome these from a system perspective, offers opportunities to combine these visions constructively into a more balanced, shared and responsible vision (Grin and Grunwald, 2000). Multi-actor dialogue meetings are perceived by some of the respondents as a strategy to 
this end. Becoming aware of the fact that one reinforces its own function and its practice, might result in discussions how the future health system should look like, where neuroimaging is envisioned to be part of. In other words, underlying the arguments used to discuss strategies to overcome the barriers, there are assumptions regarding the basic features of a desirable health system and the functioning of actors within this system.

Our research shows that a next step would be the development of an action plan and the implementation hereof through reflexive learning cycles of planning, action, observation, reflection and re-planning. This might shape technology paths towards more responsible paths and in turn, supports the process of their embedding in society. How this step will look like in detail depends on the shared desirable visions identified. It is important to note that such visions are neither a 'final state' or a consensus goal, but more a guideline for responsible monitoring. After all, as emphasised in section 2, innovations, artefacts and their socio-institutional context co-evolve during development, implementation, and use (e.g. Nelson and Winter, 1982; Schot and Rip, 1997).

We started from conclusions of previous research that the ideas of actors as a result of a CTA process generally not result in major changes of the innovation process (e.g. Grunwald, 2011; Kloet, 2011; Roelofsen, 2011; van Merkerk, 2007), probably because the socio-technical regimes are too dominant and rigid to allow changes (Kloet et al., 2013). Therefore, we analysed systemic barriers proactively throughout the process and made attempts to raise awareness and facilitate action of relevant actors regarding the existence of different visions and related (systemic) barriers to facilitate the realisation of desirable neuroimaging applications. Whether this process results in long-term effects and what these effects are, cannot be assessed yet. However, experiences with multi-actor processes such as CTA, indicate that approaches to RRI should be viewed and designed as a continual learning process (e.g. Kloet, 2011; Roelofsen, 2011; van Merkerk, 2007), in which the dimensions of anticipation, reflexivity, inclusion and responsiveness are integrated and institutionalised in and around the process of innovation development and embedding (Owen et al., 2012; Stilgoe et al., 2013). In this sense, the responsibility for and governance of RRI process is regarded as a cooperative and distributive effort: the interactions during the learning process should lead to shared, guiding visions. Our results support this conclusion and suggest that processes aiming to RRI in order to facilitate an appropriate embedding of resulting artefacts, such as the iterative ILA model, could, and perhaps should, have a structural place in any emerging science and innovation which aims to produce societal benefits. This begs the foundational question who is responsible for initialising and financing RRI processes? The majority of the respondents in our research envision the government and funding agencies as the designated point of departure, as the 
science regime has no internal drive to change the existing focus on knowledge production in absence of a central driver. In our view, a strong innovation research policy, demanding RRI designs for admissible research proposals, coaching of the granted multidisciplinary research teams and conditional mid-term evaluation on societal impact might be beneficial for wider circles of actors and society at large. By such a facilitation a structural place of RRI processes in emerging science and technology, i.e., addressing related systemic barriers, might result in a cooperative and distributive effort for the accountable financing with public money in public-private innovations.

\section{Funding}

This work was supported by the thematic programme Responsible Innovation. Ethical and societal exploration of science and technology of the Netherlands Organisation for Scientific Research (NWO) [grant number 313-99-180]. 


\section{References}

Akrich, Madeleine. "The de-scription of technical objects." In Shaping technology / building society: studies in sociotechnical change, by WE., Law, J. (eds) Bijker. Cambridge: MIT press, 1992.

Arentshorst, M. E., Broerse, J. E., Roelofsen, A. and de Cock Buning, T. "Towards Responsible Neuroimaging Applications in Health Care: Guiding Visions of Scientists and Technology Developers.” In Responsible Innovation 1', pp. 255-80. Netherlands: Springer, 2014

Arentshorst, Marlous E., Tjard de Cock Buning, and Jacqueline EW Broerse. "Exploring responsible innovation: Dutch public perceptions of the future of medical neuroimaging technology." Technology in Society 45 (2016): 8-18.

Arentshorst, Marlous E. "Future visions of medical neuroimaging: The challenge of realising responsible research and innovation." Netherlands: BOXpress, 2014.

Bijker, Wiebe E., Thomas P. Hughes, and Trevor Pinch. The social construction of technological systems. New directions in the sociology and history of technology. Cambridge, MA: MIT Press, 1987.

Broerse, Jacqueline E.W. Towards a new development strategy: How to include small-scale farmers in the technological innovation process. Delft: Eburon, 1998.

Broerse, Jacqueline EW, and Joske FG Bunders. "Requirements for biotechnology development: the necessity for an interactive an participatory innovation process.” International Journal for Biotechnology 2, no. 4 (2000): 275-296.

Broerse, Jacqueline EW, Tjard de Cock Buning, Anneloes Roelofsen, and Joske FG Bunders. "Evaluating interactive policy-making on biotechnology: the case of the Dutch ministry of health, welfare and sport." Bulletin of Science, Technology \& Society 29, no. 6 (2009): 447-463.

Chilvers, J, and P Macnaghten. The future of science governance: a review of public concerns, governance and institutional response. BIS/ Sciencewise-ERC, 2011.

Collins, H. M., and R. Evans. "The third wave of science studies: Studies of expertise and experience.” Social studies of science 32, no. 2 (2002): 235-296.

Dickstein, S G, K Bannon, F X Castekkanos, and M P Milham. "The neural correlates of attention deficit hyperactivity disorder: an ALE meta-analysis.” Journal of Child Psychology and Psychiatry 47, no. 10 (2006): 1051-1062.

Dosi, Giovanni. "Technological paradigms and technological trajectories." Research Policy 11 (1982): 147-162.

Druckman, James N, and Toby Bolsen. "Framing, motivated reasoning, and opinions about emergent technologies." Journal of Communication 61, no. 4 (2011): 659-688.

ESRC, Global Environmental Change Programme. "The politics of GM food: Risk, science and public trust.” Special briefing no 5, 1999.

Ewers, Michael, Reisa A. Sperling, William E. Klunk, Michael W. Weiner, and Harald Hampel. "Neuroimaging markers for the prediction and early diagnosis of Alzheimer's disease dementia." Trends in Neurosciences 34, no. 8 (2011): 430-424.

Fuchs, Thomas. "Ethical issues in neuroscience.” current opinion in psychiatry 19 (2006): 600-607.

Garud, R., and P. Karnøe. "Path creation as a process of mindful deviation." In Path dependence and path creation, by R. Garud and P. (Eds) Karnøe, 1-38. Mahwah, NJ: Lawrence Earlbaum, 2001.

Garud, Raghu, and Michael A. Rappa. "A socio-cognitive model of technology evolution: the case of cochlear implants.” Organization Science 5, no. 3 (1994): 344-362.

Geels, Frank W. "From sectoral systems of innovations to socio-technical systems. Insights about dynamics and change from sociology and institutional theory.” Research Policy 33 (2004): 897-920.

Glannon, W. "Neuroethics.” Bioethics 20, no. 1 (2006): 37-52.

Grin, John, and Armin Grunwald, . Vision assessment: shaping technology in 21st century society; towards a repertoire for technology assessment. Berlin: Springer, 2000.

Grunwald, Armin. “Ten Years of Research on Nanotechnology and Society- Outcomes and Achievements.” In Quantum Engagements. Social Reflections of Nanoscience and Emerging Technologies, edited by Torben Zülsdorf, Christopher Coenen, Arianna Ferrari, Ulrich Fiedeler, Colin Milburn and Matthias Wienroth, 4158. Heidelberg: Akademische Verlagsgesellschaft AKA GmbH, 2011. 
Hagendijk, Rob, and A Irwin. "Public deleberation and governance: engaging with science and technology in contemporary europe." Minerva, no. 44 (2006): 167-184.

Illes, J, and E Racine. "Imaging or imagining? A neuroethics challenge informed by genetics.” American Journal of Bioethics 5, no. 2 (2005): 5-18.

Jones, Richard. "When it pays to ask the public." Nature Nanotechnology, 2008: 578-579.

Kloet, Roy Reinier. Realizing Societal Ambitions in Innovative Research Programs. The Case of the Dutch Ecogenomics Consortium. Oisterwijk: BOXpress, 2011.

Kloet, Roy Reinier, L Hessels, Marjolein BM Zweekhorst, Jacqueline EW Broerse, and Tjard Cock Buning. "Understanding constraints in the dynamics of a research program intended as niche innovation." Science and public policy 40, no. 2 (2013): 206-218.

Loorbach, D. Transition management; new mode of governance for sustainable development. Utrecht: International Books, 2007.

Malhi, G S, and J Lagopoulos. "Making sense of neuroimaging in psychiatry.” Acta Psychiatrica Scandinavica 117, no. 2 (2007): 100-117.

Marris, C, B Wynne, B Simmons, and P Weldon. “Public perceptions of agricultural biotechnologies in Europe.” In Final report of the PABE research project. 2001.

Nelson, R. R., and S. G. Winter. An evolutionary theory of economic change. Cambridge: Harvard University Press, 1982.

Nisbet, Matthew C, and Robert K Goidel. "Understanding citizen perceptions of science controversy: bridging the ethnographic - surbey research divide.” Public Understanding of Science 16 (2007): 421-440.

Owen, Richard, and Nicola Goldberg. "Responsible innovation: A Pilot Study with the U.K. Engineering and Physical Sciences Research Council.” Risk Analysis 30, no. 11 (2010): 1699-1707.

Owen, Richard, Phil Macnaghten, and Jack Stilgoe. "Responsible research and innovation: From science in society to science for society, with society.” Science and Public Policy 39 (2012): 751-760.

Regeer, Barbara J. Making the invisible visible. Analysing the development of strategies and changes in knowledge production to deal with persistent problems in sustainable development. Oisterwijk: BOXPress, 2010.

Rip, Arie. "Futures of ELSA Science \& Society Series on Convergence Research.” EMBO reports 10, no. 7 (2009): 666-670.

Rip, Arie, Tj Misa, Schot, and John. Managing technology in society: the approach of constructuve technology assessment. London: Pinter, 1995.

Roelofsen, Anneloes. Exploring the future of ecogenomics. Constructive technology assessment and emerging technologies. Ridderkerk: Ridderprint, 2011.

Roelofsen, Anneloes, Jacqueline E W Broerse, Tjard de Cock Buning, and Joske F G Bunders. "Exploring the future of ecological genomics: integrating CTA with vision assessment.” Technological Forecasting and Social Change 75 (2008): 334-355.

Roelofsen, Anneloes, Roy Reinier Kloet, Jacqueline E W Broerse, Tjard de Cock Buning, and Joske F G Bunders. "Guiding visions in ecological genomics: a first step to exploring the future." New Genetics and Society 29, no. 1 (2010): 19-36.

Rogers-Hayden, Tee, and Nick Pidgeon. "Moving engagement "upstream"? Nanotechnologies and the Royal Society and Royal Academy of Engineering's inquiry.” Public Understanding of Science 16 (2007): 345364.

Rosas, H D, A S Feigin, and S M Hersch. "Using advances in neuroimaging to detect, understand, and monitor progression in Huntington's disease.” The Journal of the American Society for Experimental NeuroTherapeutics 1, no. 2 (2004): 263-272.

Schot, Johan, and Arie Rip. “The Past and Future of Constructive Technology Assessment.” Technological Forecasting and Social Change 54 (1997): 251-268.

Schuurbiers, Daan, and Erik Fisher. "Lab-scale intervention.” EMBO reports 10, no. 5 (2009): 424-427.

Stilgoe, Jack, Richard Owen, and Phil Macnaghten. “Developing a framework for responsible innovation.” Research Policy 42, no. 9 (2013): 1568-1580.

Szymanski, Pawel, Magdalena Markowicz, Agnieszka Janik, Mateusz Ciesielski, and Elzbieta Mikiciuk-Olasik. "Neuroimaging diagnosis in neurdegenerative dieases.” Nuclear Medicine Review 13, no. 1 (2010): 23-31.

van Merkerk, R. O. Intervening in emerging nanotechnologies: a CTA of Lab-on-a-chip technology. Utrecht: Utrecht University, 2007.

Von Schomberg, René. "Prospects for Technology Assessment in a framework of responsible research and innovation.” In Technikfolgen abschätzen lehren"Bildungspotenziale transdisziplinärer methoden, by M Dusseldorp and R Beecroft. Wiesbaden: Vs Verslag in print, 2012. 
Willmann, J K, N van Bruggen, L M Dinkelborg, and S S Gambhir. "Molecular imaging in drug development.” Nature Reviews - Drug Discovery, no. 7 (2008): 591-607.

Wilsdon, J, and R Willis. See-through science, why public engagement needs to move upstream. London: Demos, 2004. 